\title{
IMUNOGLOBULINAS G DO LIQUIDO CEFALORRAQUEANO EM AFECÇOES DO SISTEMA NERVOSO
}

\author{
J. A. LIVRAMENTO* \\ R. MELARAGNO FILHO ** \\ A. BPINA-PRRANCA ***
}

O estudo das imunoglobulinas $G$ (IGG) no líquido cefalorraqueano (LCR) vem sendo objeto de pesquisa em afeç̧ões do sistema nervoso central (SNC), visando contribuir ao problema da imunoprodução local. Esta pode ser caracterizada quando a concentração de IGG é estudada comparativamente à proteinorraquia total (relação IGG/PT) e com a prealbumino + albuminorraquia (relação IGG/PA+A). O indice de IGG (IGG LCR $\div$ IGG soro/PA+A LCR - A soro) traz também informações úteis nesse sentido $3,6,11$.

Síntese ou imunoprodução local de IGG é, assim, caracterizada em pacientes com esclerose múltipla 1,2,3,4, panencefalite esclerosante sub-aguda $7,8,12$ e moléstias inflamatórias crônicas do SNC como a neurossífilis e neurocisticercose ${ }^{9,10}$. Em meningites bacterianas agudas, tumores, acidentes cerebrovasculares e certas polineuropatias, como a diabética, pode haver aumento do teor de IGG no LCR, secundário ao comprometimento da barreira hẻmato-LCR (BHL).

Considerando os dados de normalidade próprios ao nosso meio 5,6, o objeto desta investigação é avaliar a possibilidade de imunoprodução local de IGG isto é, ao nivel do sistema LCR - mediante o estudo de pacientes nos quais o acometimento do sistema nervoso envolve processos fisiopatológicos diversos.

\section{MATERIAL E METODOS}

O estudo foi efetuado em 160 pacientes distribuidos em 8 grupos de acordo com a patologia apresentada: 1 - inflamatoria (21 casos), compreendendo 3 sub-gripos: pacientes com moléstias inflamatórias crônicas (3 casos de neurocisticercose, 1 caso de nerossifilis e 1 caso em que havia associaçăo de ambas), pacientes com encefalites agudas (2 casos) e, 14 pacientes com outras afecções inflamatórias (meningites a vírus, meningites bacterianas, suspeita clínica de neurocisticercose ou de neurossifilis, com as reacōes imunológicas especificas negativas no LCR; 2 - desmielinirante (31 casos), compreendendo 2 sub-grupos: pacientes com polirradiculoneurite (4 casos) e pacientes com diagnóstico clínico de esclerose multipla (27 casos); 3 - degenerativa, 10 pacientes com

Trabalho do Centro de Investigaç̋es em Neurologia do Departamento de Neuropsiquiatria da Faculdade de Medicina da Universidade de săo Paulo: * Médico Assistente; ** Docente Livre; *** Professor Adjunto. 
afecgres degenerativas diversas do SNC; 4 - vascular, 19 pacientes com sequelas de acidente cerebrovascular; 5 - tumoral, 3 pacientes com tumores intracranianos; - 6 epllepsia, 20 pacientes com sindrome convulsiva năo associada a outras manifestaçóes neurológicas; 7 - cefaléria, 11 pacientes com cefaléla crónica e sem outras manifestacóes neurológicas; 8 - outras patologias, 45 pacientes com patologias diversas, como traumatismo cranioencefálico, mielopatias, polineuropatias, hipertensåo intracraniana de etiologia năo esclarecida, papilite, neuralgia do trigêmio, ataxia de etiologia năo esclarecida, amaurose e calcificaçбes intracranianas de natureza nåo esclarecida.

Fim todos os pacientes fol realizado o exame do LCR, abrangendo: pressåo; citologia (contagem global e especifica); determinaça da concentraçăo de proteinas totals, cloretos a glicose; determinaça da atividade enzimática de transaminase glutamico-oxalacética e deldrogenase lática; proteinograma; estudo imunológico para sifllis e cisticercose; exame bacterioscópico e micológico, quando indicados.

Para o estudo, foram analisados os dados quanto a citologia, proteinas, participacăo (\%) de globulinas gama no perfil proteico. Fol considerada a vigência de pleocitose (mais que 4 células por $\mathrm{mm} 3$ ), de hiperproteinorraquia (mais que $30 \mathrm{mg} / 100 \mathrm{ml}$ para o LCR colhido da cisterna magna e mais que 40, para o LCR lombar) e de aumento do teor de globulinas gama (acima de 14\%).

Nos 160 pacientes fol determinada a concentraçă de IGG no LCR. Fhm 63, fol felto estudo concomitante da concentraçáo de IGG no soro e, juntamente, o estudo do proteinograma respectivo.

A concentraçă de IGG fol determinada pelo método de imunodifusăo radial de Mancini, utilizando placas Tri-Partigen para o soro e LC-Partigen para o LCR (Behringwerke, Marburg/Lahm). Os valores considerados normais tanto para a concentraça de IGG no LCR, como para as relaçes e o injlice foram publicados anteriormente 5,6: para a IGG no LCR até $3,6 \mathrm{mg}$ por $100 \mathrm{ml} \mathrm{e}$, no sangue, até 2500; para a relacăo IGG/PT, valores até 2,2; para a relaçăo IGG/PA+A, valores até 3,4 e para o indice de IGG, valores até 0,8 .

\section{RESULTADOS}

Os resultados foram distribuidos segundo os 8 grupos considerados e constam da tabela 1.

\section{COMENTARIOS}

$O$ aumento da concentração de IGG no LCR representou achado eventual entre os pacientes com cefaléia crônica, epilepsia e afeç̧ões degenerativas. Dos 41 casos desses grupos havia aumento discreto de IGG em 4; em nenhum deles as relações se encontravam alteradas.

Entre os 22 pacientes com patologia vascular ou tumoral, o aumento da concentração de IGG no LCR foi verificado em 6 . Em nenhum deles, porém, havia aumento das relações. $O$ aumento de IGG foi observado entre os 13 pacientes com hiperproteinorraquia discreta ou moderada. Tanto para a pato- 


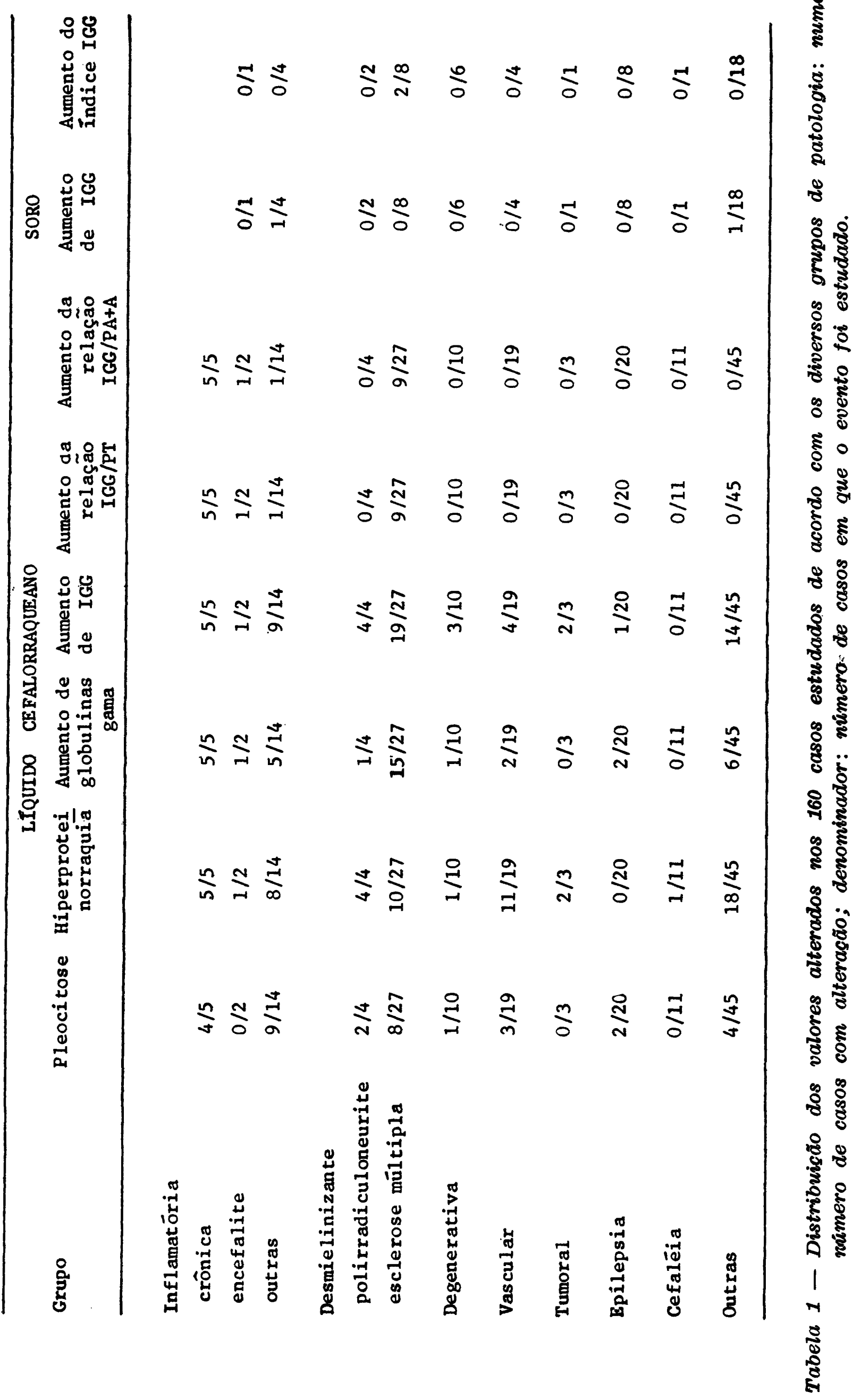


logia vascular, como para a tumoral, esta última pode ser a expressão no LCR do comprometimento da BHL pela doença. Assim sendo, o aumento de IGG pode ser considerado secundário a tal comprometimento. Ele se integra na hiperproteinorraquia.

Apesar de ocorrerem pleocitose ou hiperproteinorraquia em 18 dos 45 pacientes do grupo de outras patolugias, houve aumento de IGG no LCR em 4 apenas. Em nenhum destes havia aumento das relaçōes. Assim sendo, o aumento de IGG observado foi funçăo da hiperproteinorraquia vigente nesses casos.

Nos 14 casos do sub-grupo de outras afecções inflamatórias ocorriam alterações do dual citoproteico (pleocitose em 9 e hiperproteinorraquia em 8) e aumento de globulinas gama (5 casos). 0 aumento de IGG foi registrado em 9 casos. Apenas em 1 deles as relações encontravam-se alteradas.

Dos 2 pacientes com encefalite, apesar de não haver alterações do dual citoproteico, ocorria aumento do teor de globulinas gama em 1. Neste havia aumento de IGG acompanhado de aumento das relaçōes.

Nos 5 casos do sub-grupo de processos inflamatórios crônicos foram frequentes as alterações do dual citoproteico: havia pleocitose em 4, hiperproteinorraquia em todos e aumento do teor de globulinas gama também em todos. A concentração de IGG estava elevada nos 5 casos e o estudo das relações mostrou valores aumentados em todos.

Assim sendo, valores das relações sugestivas de produção local de imunoproteínas ocorriam em 7 dos 21 casos de pacientes com processos inflamatórios do SNC. E de notar que ocorreram em todos os casos do sub-grupo de processos inflamatórios crônicos (neurossifilis e/ou neurocisticercose), apesar de haver hiperproteinorraquia concomitante.

Nos 4 pacientes com polirradiculoneurite foi verificado aumento de IGG no LCR, o qual foi secundário à hiperproteinorraquia conforme mostram os valores normais das relações e do índice. Os aumentos foram secundários ao comprometimento da BHL, portanto. No grupo de pacientes com esclerose múltipla (27 casos) havia pleocitose discreta em 8, hiperproteinorraquia discreta em 10 e aumento discreto ou moderado do teor de globulinas gama em 15. Em 19 havia aumento do teor de IGG. As relaçōes estavam aumentadas em 9, sugerindo que pelo menos nestes casos ocorria a vigência de síntese local das imunoglobulinas $\mathrm{G}$.

$O$ indice de IGG, estudado em 53 dos 160 casos mostrou-se aumentado apenas em 2 casos. Ambos pertenciam ao grupo de pacientes com esclerose múltipla, vindo a confirmar a vigência de produção local de imunoglobulinas $\mathbf{G}$.

\section{CONCLUSOBS}

A constatação de aumento de IGG no LCR não é, por si só, dado suficiente para sugerir produção ou liberação de imunoglobulinas ao nivel do SNC. Ela pode ser secundária a hiperproteinorraquia resultante de comprometimento da barreira hêmato-LCR, por exemplo. 
Para configurar a hipótese de produção local dessas imunoproteínas é necessário relacionar a concentração de IGG no LCR à proteinorraquia total e à albuminorraquia + prealbuminorraquia. É útil também o estudo do índice de IGG. Só quando valores acima do normal são encontrados para tais relações e/ou para o indice é que se pode considerar a vigência de atividade imunológica local imunoproducente. Entre os 160 casos que compõem a série analisada ela foi configurada em 16, todos com esclerose múltipla ou processos inflamatórios, especialmente crônicos (neurossifilis, neurocisticercose).

\section{RBPSUMO}

Foi estudado o comportamento da imunoglobulina G (IGG) e de suas relações com a proteinorraquia (IGG/PT) e com a prealbumino + albuminorraquia $(I G G / P A+A)$ e o indice de IGG em 160 pacientes com afecções diversas do sistema nervoso, distribuídas em 8 grupos de acordo com a patologia apresentada: inflamatória, desmielinizante, degenerativa, vascular, tumoral, epilepsia, cefaléia, outras. $O$ indice de IGG foi estudado em 53 desses casos. De acordo com os resultados encontrados a maior aplicabilidade do estudo das imunoglobulinas do LCR verifica-se nos dois primeiros grupos de patologia estudados ou seja, o grupo inflamatório - sobretudo o sub-grupo de patologia inflamatória crônica, como a neurossifilis e a neurocisticercose - e o grupo de afecções desmielinizantes, nele salientando-se o sub-grupo de pacientes com esclerose múltipla. Enfase é dada a avaliação da possibilidade da ocorrência de imunoprodução local de IGG, só configurada nesses dois grupos em função do aumento das relações $e$ do indice.

\section{SUMMARY}

\section{Cerebrospinal fluid immunoglobulin $G$ in disorders of the nervous system.}

Cerebrospinal fluid IGG and the relations with total protein, and with prealbumin + albumin and the IGG index were studied in 160 patients with various neurological disorders. These patients were distributed in 8 groups according to diagnosis as follows: inflammatory (21 casts); demyelinating (31 cases); degenerative (10 cases); cerebrovascular (19 cases); tunıral (3 cases); convulsive (20 cases); headache (11 cases); other neurological disorders (45 cases). According to the results (table 1) the best aplicability of IGG study is the group of chronic inflammatory diseases (neurosyphilis and neurocysticercosis) and the demyelinating disorders (multiple sclerosis). Emphasis is given to the possibility of the occurrence of local synthesis of IGG in the central nervous system in these 2 groups.

\section{RERPERENCIA}

1. HICKHOFT, K. KASCHKA, W.; SKVARIL, F.; THEILKAFS, L. \& HEIPERTZ, R. - Determination of IgG subgroups in cerebrospinal fluid of multiple sclerosis patients and others. Acta neurol. scand. 60:277, 1979. 
2. KOLAR, O. J.; ROSS, A. T. \& HERMAN, J. T. - Serum and cerebrospinal fluid immunoglobulins in multiple sclerosis. Neurology (Minneap.) 20:1052, 1970.

3. LINK, H. \& TIBBLING, G. - Principles of albumin and IGG analyses in neurological disorders. II - Relation of the concentration of the proteins in serum and cerebrospinal fluid. Sand. J. clin. Lab. Invest. 37:391, 1977.

4. LINK, H. \& TIBBLING, G. - Principles of albumin and IGG analyses in neurological disorders. III - Evaluation of IGG synthesis within the central nervous system in multiple sclerosis. Scand. J. clin. Lab. Invest. 37:397, 1977.

5. LIVRAMENTO, J. A. - Imunoglobulinas do líquido cefalorraqueano normal. Arq. Neuro-psiquiat. (São Paulo) 37:230, 1979.

6. LIVRAMENTO, J. A. - Imunoglobulinas do liquido cefalorraqueano normal. II Relações e indices. Arq. Neuro-Psiquiat. (São Paulo) 37:397, 1979.

7. NERENBERG, S. T.; PRASAD, R. \& ROTHMAN, M. E. - Cerebrospinal fluid IgG, IgA, IgM, IgD and IgE levels in central nervous system disorders. Neurology (Minneap.) 28:988, 1978.

8. SAVORY, J. \& HEINTGES, M. G. - Cerebrospinal fluid levels of IGG, IGA and IGM in neurologic diseases. Neurology (Minneap.) 23:963, 1973.

9. SPINA-FRANÇA, A.; LIVRAMENTO, J. A. \& BACHESCHI, L. A. - Gamaglobulinorraquia e o aspecto autolmune de afeções do sistema nervoso. Resumo - VI Congresso Brasileiro de Neurologia (Rio de Janeiro) 1974, pág. 13.

10. SPINA-FRANÇA, A.; LIVRAMENTO, J. A.; BACHESCHI, L. A. \& GARCIA-LOPES, P. - Cerebrospinal fluid immunoglobulins in cysticercosis of the central nervous system. Arq. Neuro-Psiquiat. (São Paulo) 34:40, 1976.

11. TIBBLING, G.; LINK, H. \& OHMAN, S. - Principles of albumin and IGG analyses in neurological disorders. I - Establishment of reference values. Scand. J. clin. Lab. Invest. 37:385, 1977.

12. TOURTELLOTTE, W. W. - On cerebrospinal fluid immunoglobulin G (IGG) quotients in multiple sclerosis and other diseases. J. neurol. Sci. 10:279, 1970.

Centro de Investigaçes em Neurologia - Calba Postal 5199 - 01000 são Paulo, SP - Brasil. 